'Abteilung Rheumatologie und klinische Immunologie, ${ }^{2}$ Abteilung Hämatologie und Onkologie, Medizinische Klinik, Freiburg, Germany

\title{
Monocyte Differentiation and Accessory Function: Different Effects on the Proliferative Responses of an Autoreactive T Cell Clone as Compared to Alloreactive or Antigen-Specific T Cell Lines and Primary Mixed Lymphocyte Cultures
}

\author{
Michael Schlesier ${ }^{1}$, Stefan Krause ${ }^{2 *}$, Ruth Dräger ${ }^{1}$, Guido Wolff- \\ VORBeCK ${ }^{1}$, Marina KReUTZ ${ }^{2 *}$, Reinhard ANDREeSEN ${ }^{2 *}$, and Hans-Hart- \\ MUT PETER ${ }^{1}$
}

Received June 3, $1993 \cdot$ Accepted in revised form October 29, 1993

\begin{abstract}
An autoreactive $\mathrm{T}$ cell clone derived from a patient with reactive arthritis, two alloreactive $T$ cell lines, two antigen-specific $T$ cell lines and allogeneic resting $T$ cells were analyzed for their responses to monocytes and macrophages derived from monocytes by in vitro differentiation. The autoreactive $\mathrm{T}$ cell clone strongly proliferated in response to fresh monocytes and to macrophages derived from a 7 day culture, but only poorly to monocytes cultured for 2 days. In contrast, alloreactive and antigen-specific $T$ cell lines proliferated to all stimulator cells equally well. Finally, primary mixed lymphocyte reactions could be stimulated by both fresh and 2-day cultured monocytes, but not by in vitro derived macrophages. The impaired response of the autoreactive $\mathrm{T}$ cell clone to 2day cultured monocytes could not be attributed to reduced expression of several welldefined surface molecules nor to induction of nonresponsiveness. Neither allogeneic monocytes nor cytokines (IL-1, IL-2, IL-4, IL-6) could correct the defective response of the autoreactive $\mathrm{T}$ cell clone. However, preculture of monocytes in the presence of interferon-gamma, IL-1, IL-4 or IL-6 retained their stimulatory capacity. Our interpretation of the selectively impaired response of the autoreactive $\mathrm{T}$ cell clone is that it most likely recognizes a differentiation-dependent monocyte/macrophage-specific peptide.
\end{abstract}

\footnotetext{
* Current address: Klinik für Innere Medizin I, Franz-Josef-Strauß-Allee 11, 93053 Regensburg, Germany
} 


\section{Introduction}

$T$ cell activation requires a complex interplay of antigen-specific $T$ cellaccessory cell interactions via TCR/CD3-MHC/peptide complex and antigen-independent interactions via adhesion molecules, costimulatory ligands and cytokines (1). Monocytes and dendritic cells are considered to be professional accessory cells capable of stimulating both primary and secondary $\mathrm{T}$ cell responses (2). On the other hand, the dominant function of tissue macrophages is phagocytosis and cytotoxicity, while accessory functions are strongly reduced (3-5). Monocyte differentiation to macrophageor dendritic-like phenotypes can be induced by in vitro culture in the presence of serum (6-9). Similar to tissue macrophages, in vitro matured macrophages show impaired accessory functions in mitogen-induced $\mathrm{T}$ cell responses $(9,10)$ and mixed lymphocyte reactions $(6)$. The present study was performed to test the ability of in vitro differentiated monocytes to stimulate different secondary $\mathrm{T}$ cell responses. It turned out that antigenspecific and alloreactive $\mathrm{T}$ cell lines could be equally restimulated by different monocyte differentiation stages, while an autoreactive $\mathrm{T}$ cell clone was selectively unable to recognize monocytes cultures for 2 days.

\section{Materials and Methods}

\section{Blood donors}

Mononuclear cells (MNC) and T cell lines were derived from donor UA (HLA A2,32; B27, 51; DR11.1, 11.3) (11) and donor MS (HLA A1; B8, w60; DR3, 11.1). Additional HLA-taped MNC and EBV-transformed B cell lines were kindly provided by Dr. ARLetTe URLACHER (Blood Bank, Strasbourg, France).

\section{Establishment of T cell lines}

The origin and specificity of $\mathrm{T}$ cell lines used in this study is summarized in Table 1. The autorective T cell clone UA-S2 was derived from IL-2-supplemented limiting dilution cultures of synovial fluid lymphocytes of patient UA suffering from reactive arthritis (11). UA-S2 recognizes a so far unknown peptide in association with HLA-DR 11.3 (11, 12). The expressed TCR $\alpha$ and $\beta$ chains of UA-S2 have been sequenced (13). The alloreactive T cell clone MS-UA-B12 was derived by stimulation of MNC from donor MS with irradiated MNC from donor UA under limiting dilution conditions. It recognizes HLA-DR 11.3-typed and some DR 11.4-typed MNC or B cell lines (not shown). The alloreactive cell line PLT->UA was produced by a primary stimulation of lymphocytes of donor NN (not HLA-typed) with irradiated MNC from donor UA in bulk culture and shows a proliferative response to all DR 11 positive MNC or B cell lines (not shown). Similarly, cell line PLT->MS was established using stimulator cells from donor MS. Antigen-specific T cell clones MS-PPD-B5 and MS-PEP-N1 were derived from primary cultures of MNC from donor MS stimulated with PPD $(25 \mu \mathrm{g} / \mathrm{ml}$, Behring, Marburg, Germany) or pork pepsin (1 $\mathrm{\mu g} / \mathrm{ml}$, Sigma, München, Germany) and subsequent limiting dilution cloning and subcloning (14). The phenotype of all $\mathrm{T}$ cell lines was $\mathrm{TcR} \alpha \beta^{+} \mathrm{CD} 3^{+} \mathrm{CD} 4^{+} \mathrm{CD} 8^{-} \mathrm{CD} 29^{\text {high }}$. 
$\mathrm{T}$ cell lines were maintained in medium RPMI 1640 supplemented with penicillin (100 $\mathrm{U} / \mathrm{ml})$, streptomycin $(100 \mu \mathrm{g} / \mathrm{ml})$, glutamine $(2 \mathrm{mM}), 10 \%$ FCS (all reagents from Biochrom, Berlin, Germany), $2.5 \%$ human $\mathrm{AB}$ serum and highly purified human natural IL-2 $(20 \mathrm{U} / \mathrm{ml}$, Biotest, Dreieich, Germany). For primary cultures $10 \%$ autologous serum was used instead of FCS. Every two weeks, the T cell lines were restimulated with irradiated (30 Gy) allogeneic MNC and monoclonal anti-CD3 antibody BMA030 (10 ng/ $\mathrm{ml}$, Behring). Mycoplasma contaminations were excluded by periodical assays for mycoplasmal adenosine phosphorylase (MycoTect, Gibco, Grand Island, NY, USA) using mouse $3 \mathrm{~T} 3$ fibroblasts as indicator cells for toxic substrate formation.

\section{Separation of mononuclear cell fractions}

MNC were isolated from cytapheresis concentrates of donors UA or MS by Ficoll density gradient centrifugation. Lymphocyte- and monocyte-enriched fractions were prepared by countercurrent centrifugal elutriation in a Beckman J2/21 as described in detail by ANDREESEN et al. (15) and cryopreserved in small aliquots in liquid nitrogen in the presence of $50 \% \mathrm{FCS}$ and $10 \% \mathrm{DMSO}$. The monocyte-enriched fractions from donors UA and MS contained $70 \%$ and $83 \% \mathrm{CD}^{+} 4^{+}$cells, respectively. The lymphocyte-enriched fractions contained less than $0.3 \% \mathrm{CD}^{+} 4^{+}$cells.

\section{Monocyte culture}

Monocyte-enriched cell fractions were carefully thawed at appropriate time points by stepwise addition of RPMI 1640 at $4^{\circ} \mathrm{C}$ and washed twice with medium $(300 \times \mathrm{g}, 10 \mathrm{~min}$, $4{ }^{\circ} \mathrm{C}$ ). The recovery of vital cells (trypan blue exclusion) was always greater than $80 \%$. Cells were resuspended in RPMI 1640 supplemented with antibiotics, glutamine and $2 \%$ human $\mathrm{AB}$ serum and seeded at different cell concentrations $\left(1 \times 10^{3}\right.$ to $\left.4 \times 10^{4}\right)$ into flat bottom microtiter ELISA plates (Greiner, Nürtingen, Germany). After $2 \mathrm{~h}$ non-adherent cells were removed by washing the plates with medium twice. Cultures were continued in RPMI $1640+2 \% \mathrm{AB}$ serum for 2 or 7 days. Where indicated, recombinant human cytokines were added from the start of cultures (interferon-gamma, rhIFN-gamma, 200 $\mathrm{U} / \mathrm{ml}$, Bioferon, Laupheim, Germany; interleukin-1 $\beta, \mathrm{rhIL}-1,1 \mathrm{ng} / \mathrm{ml}$, kindly provided by Dr. W. ConCA, Freiburg; interleukin-4, rhIL-4, $100 \mathrm{U} / \mathrm{ml}$, kindly provided by Dr. S. GiLlis, Immunex, Seattle, WA, USA; interleukin-6, rhIL-6, $100 \mathrm{U} / \mathrm{ml}$, Boehringer, Mannheim, Germany).

\section{Proliferative response}

After $2 \mathrm{~h}, 2$ days or 7 days of monocyte culture the medium was replaced by test medium (RPMI $1640+10 \%$ FCS $+2.5 \%$ human pooled serum). At these time points, viability of the cultures was checked microscopically and in some experiments by MTT reduction tests (not shown) of parallel cultures. T cell lines were added to the adherent cell layer at $2 \times 10^{4}$ per well. In the case of antigen-specific $\mathrm{T}$ cell lines, assays were performed in parallel with and without antigens $(25 \mu \mathrm{g} / \mathrm{ml}$ PPD or $1 \mu \mathrm{g} / \mathrm{ml}$ pepsin). Some assays were supplemented with cytokines (concentrations indicated above), anti-CD3 antibody (BMA030, $10 \mathrm{ng} / \mathrm{ml}$ ), anti-CD 28 antibody $(9.3,1: 8000$, kindly provided by Dr. J. A. LEDBETTER, Seattle, WA, USA), or allogeneic monocyte enriched cell fraction $\left(2 \times 10^{4} /\right.$ well). In some experiments, anti-CD3 antibody or fresh autologous monocytes were added $24 \mathrm{~h}$ later. The cultures were pulsed $(18 \mathrm{~h})$ with ${ }^{3} \mathrm{H}$-thymidine after $48 \mathrm{~h}$. For MLC cultures allogeneic lymphocytes, depleted from monocytes by counterflow centrifugation, were added at $1 \times 10^{5}$ per well and pulsed with ${ }^{3} \mathrm{H}$-thymidine after 5 days. Proliferative responses are given in counts per $\min (\mathrm{cpm})$ and represent the mean of triplicates; standard deviations were sometimes elevated due to inhomogenous distribu- 
tion of monocytes in the wells but always below $25 \%$. Background ${ }^{3} \mathrm{H}$-thymidine uptake of monocytes was usually below $200 \mathrm{cpm}$ and was subtracted.

\section{Surface antigen expression}

$\mathrm{T}$ cell lines were phenotyped by flow cytometry (FACStar Plus, Becton-Dickinson) using phycoerythrin- or fluorescein-conjugated monoclonal antibodies: anti-TcR $\alpha \beta$ (BMA031, Behring), anti-CD3 (UCHT1) and anti-CD8 (DK25, Dako), anti-CD4 (IOT4, Dianova-Immunotech), anti-CD29 (4B4, Coulter). Monocyte surface antigen expression was evaluated either by cell ELISA or by flow cytometry. The cell ELISA system has been described previously (15). Briefly, monocytes were cultured in microtiter plates as described above, fixed at $4{ }^{\circ} \mathrm{C}$ with $0.05 \%$ glutaraldehyde for $10 \mathrm{~min}$ and treated with monoclonal antibodies against $\beta_{2}$-microglublin $(\beta 2 \mathrm{M}$, Becton Dickinson), CD14 (My4, Coulter), HLA-DR/DP (Tü39, Biotest) and the differentiation-dependent antigen gp68-MAX.3 (16). Specifically bound antibodies were detected by peroxidaseconjugated second antibody, developed with phenyl-diaminedichloride and optical density was read at $486 \mathrm{~nm}$. Results are given as percentage of $\beta 2 \mathrm{M}$ expression (antigen expression index). For flow cytometric analysis, monocytes were cultured in teflon bags (7). Cells were stained by direct (CD14, My4, Coulter; HLA-DR, Becton-Dickinson; ICAM-1, CD54, Dianova-Immunotech; all antibodies fluorescein-conjugated) or indirect immunofluorescence (LFA-3, TS2.9, kindly provided by Dr. S. C. MeuER, Heidelberg; second antibody: fluorescein-conjugated goat- $\mathrm{F}(\mathrm{ab})_{2}$-anti-mouse-IgG, Dianova, Hamburg, Germany). Staining was performed in the presence of $1 \%$ human IgG to reduce unspecific binding. Isotype matched mouse IgG (Becton-Dickinson) was used for control staining.

\section{Results}

We used a monocyte culture system in microtiter plates to investigate the effect of differentiation on auto-, allo- and soluble antigen induced $\mathrm{T}$ cell proliferation. Monocyte differentiation into mature macrophages was monitored microscopically and by expression of the macrophage marker MAX.3 (Tab. 2). Analysis of monocyte surface markers known to be involved in $\mathrm{T}$ cell activation (HLA-DR, CD14, ICAM-1, LFA-3) did not reveal any major changes of expression during monocyte cultures (Tab. 2).

Various $T$ cell lines with different specificities (Tab. 1) and resting monocyte-depleted T cells were cocultured with monocytes or accessory

Table 1. Characterization of $\mathrm{T}$ cell lines.

\begin{tabular}{|c|c|c|c|c|c|}
\hline & $\mathrm{UA}^{-S 2^{\mathbf{a}}}$ & MS-UA-B12 & $\mathrm{PLT} \rightarrow \mathrm{UA}$ & MS-PPD-B5 & MS-PEP-N $1^{b}$ \\
\hline Donor & UA & MS & NN & MS & MS \\
\hline Primary & & & & & \\
\hline stimulation & IL-2 & UA & UA & PPD & pepsin \\
\hline Specificity & autoreactive & alloreactive & autoreactive & PPD & pepsin \\
\hline Restriction & DR 11.3 & DR 11.3 & DR 11 & DR 3 & DR 3 \\
\hline
\end{tabular}

${ }^{a}$ SChlesier et al. (11); ${ }^{b}$ Lacour et al. $(14,34)$ 
Table 2. Phenotypical characterization of cultured monocytes.

\begin{tabular}{|c|c|c|c|c|c|c|c|c|c|c|c|c|}
\hline \multirow{3}{*}{$\begin{array}{l}\text { Monocyte } \\
\text { culture }\end{array}$} & \multicolumn{12}{|c|}{ Phenotype } \\
\hline & \multicolumn{4}{|c|}{ Cell ELISA } & \multicolumn{8}{|c|}{ Flow cytometry ${ }^{b}$} \\
\hline & $\beta 2 \mathrm{M}$ & CD14 & MAX. 3 & HLA-DR & Control & $\mathrm{CD}$ & & $\mathrm{HL}$ & A-DR & ICAM-1 & $\mathrm{LF}$ & \\
\hline Day 0 & 1.8 & 85 & 12 & 96 & 190 & 600 & $(90)$ & 510 & (93) & $390 \quad(97)$ & 455 & (99) \\
\hline Day 2 & 1.8 & 86 & 27 & 85 & 210 & 610 & (82) & 590 & (87) & $620 \quad(87)$ & 520 & (87) \\
\hline Day 7 & 2.2 & 112 & 58 & 110 & 300 & 670 & (96) & 590 & (77) & $690 \quad(90)$ & 610 & (95) \\
\hline
\end{tabular}

Antigen expression index calculated on the basis of $\beta 2$-microgobulin $(\beta 2 \mathrm{M})$ expression $\left(\mathrm{OD}_{486}\right)(15)$.

b Mean channel fluorescence (\% positive cells) measured with a FACStar Plus (Becton-Dickinson). The table shows representative data from 1 out of 2 experiments that are in accordance with previously published results (15). 
cells derived from monocytes by culture for 2 or 7 days. Experiments with monocytes derived from 2 donors (Fig. 1) revealed that the alloreactive $T$ cell clone MS-UA-B12 and 2 alloreactive T cell lines (PLT $->$ UA and PLT - > MS) were stimulated equally by all monocyte differentiation stages (Fig. 1A). The same was true for the antigen-specific T cell clones MS-PPDB5 and MS-PEP-N1 (Fig. 1B). On the contrary, primary alloreactive T cell responses (MLC) could be equally stimulated by fresh and 2-day cultured monocytes but not by macrophages derived from 7-day cultures (Fig. 1C).

In clear contrast to the alloreactive and antigen-specific responses, the autoreactive T cell clone UA-S2 of synovial fluid origin did not respond to 2-day cultured monocytes in several independent experiments, although strongly proliferating in response to fresh monocytes and in vitro derived macrophages (Fig. 1D). The impaired stimulatory capacity of monocytes

A secondary alloreactive response

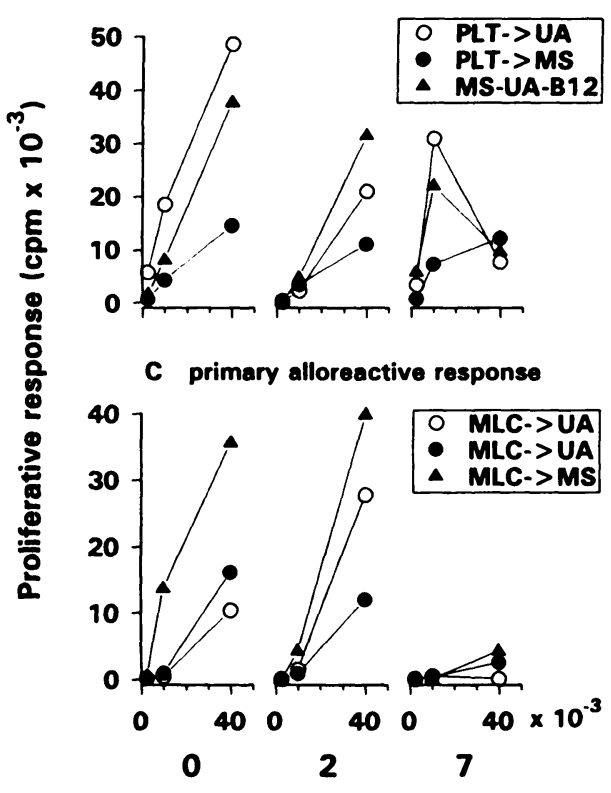

B secondary soluble antigen response

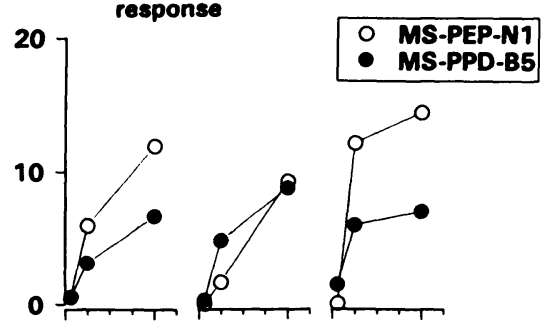

D autoreactive response

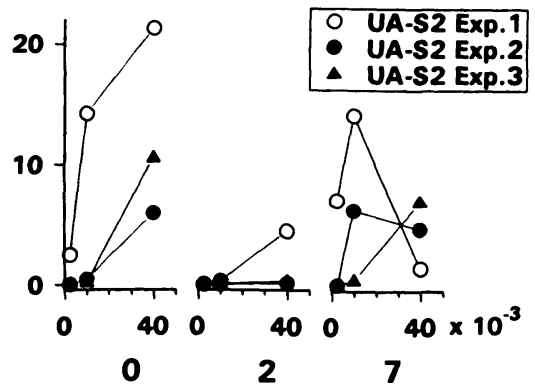

\section{Monocyte culture (days)}

Figure 1. Response of alloreactive, antigen-specific and autoreactive $\mathrm{T}$ cells to different maturation stages of monocytes. Appropriate elutriation-enriched monocytes of donor UA or MS were seeded in microtiter plates at $2.5 \times 10^{3}, 1 \times 10^{4}$ and $4 \times 10^{4}$ cells/well. (A, B, D) Various $\mathrm{T}$ cell lines $\left(2 \times 10^{4}\right)$ or $(\mathrm{C})$ monocyte depleted lymphocytes (MLC, $1 \times 10^{5}$ ) were added either immediately (day 0 ) or after 2 days or 7 days of monocyte preculture. Antigens (pepsin or PPD) were included in assays with antigen-specific $T$ cell clones (B); proliferative responses in the absence of antigens were always below $200 \mathrm{cpm}$. Proliferative responses were quantified by a $18 \mathrm{~h}$ pulse of ${ }^{3} \mathrm{H}$-thymidine after $48 \mathrm{~h}$ in the case of secondary responses or after 5 days in the case of MLC. Individual experiments are shown for all cell types. 
Table 3. Impaired stimulation of UA-S2 by 2 day cultured monocytes is not due to suppression.

Stimulus

Proliferative

response $(\mathrm{cpm})$

Medium

Anti-CD3

Fresh monocytes

Fresh monocytes + anti-CD3

$2 \mathrm{~d}$ monocytes

$2 \mathrm{~d}$ monocytes + anti-CD3

10440

$2 \mathrm{~d}$ monocytes + fresh monocytes

7710

$7 \mathrm{~d}$ monocytes

6210

$7 \mathrm{~d}$ monocytes + anti-CD3

9360

$7 \mathrm{~d}$ monocytes + fresh monocytes

5600

UA monocytes were seeded at $4 \times 10^{4}$ per well and precultured for 2 or 7 days in RPMI 1640 medium supplemented with $2 \%$ AB serum. Fresh UA monocytes were added at $4 \times 10^{4}$ per well and anti-CD3 antibody (BMA030) at $10 \mathrm{ng} / \mathrm{ml}$. UA-S2 $\left(2 \times 10^{4}\right.$ per well) was cocultured for $48 \mathrm{~h}$ and then pulsed with ${ }^{3} \mathrm{H}$-thymidine for additional $18 \mathrm{~h}$.

already became obvious after a one day culture and lasted for 4 days (not shown) and was observed with a wide range of monocyte concentrations tested (up to $1 \times 10^{5}$ cells/well). In contrast, primary and secondary alloreactive responses tested in parallel during the same experiment were never decreased at day 2 of monocyte culture, thus excluding experimental variations in monocyte cultures as the cause of impairement. Addition of anti-CD3 antibody or fresh autologous monocytes completely restored the response of UA-S2 to 2-day cultured monocytes (Tab. 3) excluding suppressive effects of the "medium-aged" macrophages. More importantly, even the delayed addition of anti-CD3 or fresh monocytes restored the proliferative response of UA-S2 also excluding induction of nonresponsiveness as the underlying mechanism (Tab. 4). In contrast, the impaired response to 2-day cultured monocytes could neither be restored by addition of cytokines (IL-1, IL-4, IL-6) or anti-CD28 antibody, nor by addition of allogeneic monocytes. However, monocytes precultured during 2 days in the presence of IFN-gamma were still able to induce UA-S2 proliferation ( $3310 \mathrm{cpm}$ vs. $740 \mathrm{cpm}$ with IFN-gamma vs. medium cultured monocytes). A similar but less pronounced effect was observed after monocyte precultures in the presence of IL-1, IL-6, and IL-4 (not shown).

\section{Discussion}

In this study we evaluated the effect of in vitro maturation on accessory function of monocytes/macrophages. In contrast to monocytes, in vitro differentiated macrophages were only weak stimulators of primary alloreac- 
Table 4. Impaired stimulation of UA-S2 by 2-day cultured monocytes is not due to induction of nonresponsiveness and cannot be restored by cytokines or allogeneic monocytes.

\begin{tabular}{llrr}
\hline $\begin{array}{l}\text { Presence of } \\
\text { 2-day cultured } \\
\text { UA monocytes }\end{array}$ & Supplementation & \multicolumn{2}{c}{ Proliferative response } \\
\cline { 3 - 4 } \cline { 3 - 4 } & & UA-S2 & B12 \\
\hline- & Medium & 12 & 11 \\
- & IL-2 $(20 \mathrm{U} / \mathrm{ml})$ & 22 & 180 \\
- & Fresh UA monocytes & 4680 & 3910 \\
+ & Medium & 740 & 4510 \\
+ & anti-CD3 (10 ng/ml) after $24 \mathrm{~h}$ & 6690 & 6150 \\
+ & fresh UA monocytes after $24 \mathrm{~h}$ & 3510 & 7610 \\
+ & IL-2 $(20 \mathrm{U} / \mathrm{ml})$ & 2170 & 5110 \\
+ & rhIL-4 $(100 \mathrm{U} / \mathrm{ml})$ & 880 & 5680 \\
+ & rhIL-1 $(1 \mathrm{ng} / \mathrm{ml})$ & 1320 & 6320 \\
+ & rhIL-6 $(100 \mathrm{U} / \mathrm{ml})$ & 1170 & 5950 \\
+ & anti-CD28 $(9.3 ; 1: 8000)$ & 960 & 4020 \\
+ & allogeneic monocytes & 860 & 7090 \\
\hline
\end{tabular}

UA monocytes were seeded at $4 \times 10^{4}$ per well and precultured for 2 days in RPMI 1640 medium supplemented with $2 \% \mathrm{AB}$ serum. At the day of assay the medium was replaced by RPMI 1640 medium with $10 \%$ FCS and $2 \%$ AB serum; UA-S2 or MS-UA-B12 were added at $2 \times 10^{4}$ per well. Cytokines, monoclonal antibodies, allogeneic monocytes from donor MS $\left(2 \times 10^{4}\right.$ per well $)$ or fresh UA monocytes $\left(2 \times 10^{4}\right.$ per well $)$ were added either simultaneously or after $24 \mathrm{~h} .48 \mathrm{~h}$ after onset the assay was pulsed with ${ }^{3} \mathrm{H}$-thymidine for additional $18 \mathrm{~h}$. The data represent a typical experiment out of 3 similar experiments.

tive $T$ cell responses which is consistent with other reports $(5,10)$. Similarly, primary T cell responses cannot be induced by fixed APC (17), B cell lines (18) or interferon-gamma-treated endothelial cells, fibroblasts or chondrocytes $(19,20)$, a failure supposed to be due to insufficient or altered production of necessary costimulatory signals, cytokines or processed antigen peptides (21).

On the other hand, it is widely accepted that induction of secondary $\mathrm{T}$ cell responses is not strictly dependent on professional APC. Human T cell lines have been shown to respond to alloantigens and soluble antigens presented by B cell lines (22) or IFN-gamma-treated fibroblasts, endothelial cells (19) or chondrocytes (20). In this study we extend this listing by demonstrating that in vitro derived macrophages, in contrast to their inability to stimulate primary responses, are clearly capable of stimulating secondary alloreactive and antigen-specific responses as efficiently as monocytes. Similarly, in the murine system, antigen-specific $T$ cell lines could be restimulated by antigens presented on peritoneal macrophages (23, 24). On the basis of the above-mentioned facts the response pattern of the autoreactive $\mathrm{T}$ cell clone UA-S2 is most striking. The inability of mono- 
cytes cultured for 2 days to stimulate UA-S2 cannot be attributed to a deficient costimulatory signal because of the following reasons: i) various secondary and even primary $\mathrm{T}$ cell responses were stimulated equally well by cultured monocytes, ii) molecules necessary in $\mathrm{T}$ cell-monocyte interactions like HLA-DR, CD14, LFA-3, and ICAM-1 were not deficient on cultured monocytes, iii) allogeneic monocytes, cytokines $(25,26)$, and antiCD28 antibody (27) could not restore the impaired response, and most importantly, iv) nonresponsiveness that is induced by APC in the absence of adequate costimulation (27) was not observed with UA-S2, since the clone was fully responsive to fresh monocytes or anti-CD3 antibody after preincubation with cultured monocytes for $24 \mathrm{~h}$. Therefore we propose that the only plausible explanation for the failure of cultured monocytes to stimulate UA-S2 is the lacking presentation of the peptide recognized by the $\mathrm{T}$ cell receptor of UA-S2. This peptide may be either derived from a differentiation-dependent monocyte-specific protein or produced by a differentiation-dependent protease. This suggestion is in agreement with the observed major changes in phenotype and enzyme content after 2 days of culture during in vitro differentiation of monocytes to macrophages (8, $15,28)$. It also explains the failure of an autologous B cell line to stimulate UA-S2 (11). Although cell type-restricted autoreactive $\mathrm{T}$ cells have been described, the nature of the peptides recognized has not been uncovered (29). This is, to our knowledge, the first report on a differentiationdependent autoreactive response. Culture-dependent loss of antigen-presenting ability for exogenous soluble antigens has been described for murine macrophages and explained by the inability of cultured APC to produce the correct peptides due to changes in the proteolytic system (24).

The cytokines IFN-gamma, IL-1, IL-6, and IL-4 to some extent retained the stimulatory potential of cultured monocytes in the UA-S2 system. This may be due to the documented effects of these cytokines on differentiation and accessory function. Especially IFN-gamma is a strong enhancer of accessory activity due to upregulation of several surface molecules like MHC class II antigens, ICAM-1 and B7/BB1 (19, 30-32). IL-1, IL-6, and IL-4 have been shown to augment the accessory potency of cultured monocytes in mitogen-driven $\mathrm{T}$ cell responses $(28,33)$. Thus, culture of monocytes in the presence of these cytokines may induce and/or maintain the presentation of the antigenic peptide to UA-S2.

\section{Acknowledgements}

We thank Dr. A. UrLacher (Strasbourg) and Dr. W. Conca (Freiburg) for critical discussions and valuable suggestions and for providing typed cells and recombinant IL-1, respectively; Drs. J. A. LeDBETTER (Seattle) and S. C. MeUER (Heidelberg) for providing monoclonal antibodies. This work was supported by BMFT grant 01 VM8908. 


\section{References}

1. Altman, A., K. M. Coggeshall, and T. Mustelin. 1990. Molecular events mediating $T$ cell activation. Adv. Immunol. 48: 227.

2. WeAver, C. T., and E. R. UNANUE. 1990. The costimulatory function of antigenpresenting cells. Immunol. Today 11: 49.

3. FuRTh, R. VAN. 1982. Current view on the mononuclear phagocyte system. Immunobiol. 161: 178.

4. Johnston JR., R. B. 1988. Monocytes and macrophages. N. Engl. J. Med. 318: 747.

5. EtTensohn, D. B., P. G. Duncan, and M. J. Jankowski. 1989. The role of human alveolar macrophages in the allogeneic and autologous mixed leucocyte reactions. Clin. Exp. Immunol. 75: 432.

6. Rinehart, J. J., M. Orser, and M. Kaplan. 1979. Human monocyte and macrophage modulation of lymphocyte proliferation. Cell. Immunol. 44: 131.

7. Andreesen, R., J. PiCht, and G. W. Lohr. 1983. Primary cultures of human bloodborn macrophages grown on hydrophobic teflon membranes. J. Immunol. Methods 56: 295.

8. Akiyama, Y., R. Griffith, P. Miller, G. W. Stevenson, S. Lund, D. J. Kanapa, and H. C. STEVenson. 1988. Effects of adherence, activation and distinct serum proteins on the in vitro human monocyte maturation process. J. Leukoc. Biol. 43: 224.

9. Peters, J. H., S. Ruhl, and D. Friedrichs. 1987. Veiled accessory cells deduced from monocytes. Immunobiol. 176: 154.

10. Mayernik, D. G., A. Ul Haq, and J. J. Rinehart. 1983. Differentiation-associated alteration in human monocyte-macrophage accessory cell function. J. Immunol. 130: 2156.

11. SChlesier, M., C. Ramb-Lindhauer, R. Dräger, A. Urlacher, M. Robin-WinN, and H. H. Peter. 1988. Autoreactive T cells in rheumatic disease. II. Function and specificity of an autoreactive $\mathrm{T}$ helper cell clone established from a HLA-B27+ reactive arthritis. Immunobiol. 177: 420.

12. Steimle, V., A. Hinkkanen, M. Schlesier, and J. T. Epplen. 1988. A novel HLADR beta I sequence from the DRw11 haplotype. Immunogenetics 28: 208.

13. Hinkkanen, A. E., V. Steimle, M. Schlesier, H. H. Peter, and J. T. Epplen. 1989. The antigen receptor of an autoreactive $\mathrm{T}$ cell clone from human rheumatic synovia. Immunogenetics 29: 131.

14. Lacour, M., U. Rudolphi, M. Schlesier, and H. H. Peter. 1990. Type II collagen-specific human $\mathrm{T}$ cell lines established from healthy donors. Eur. J. Immunol. 20: 931.

15. Andreesen, R., W. Brugger, C. Scheibenbogen, M. Kreutz, H. G. Leser, A. REHM, and G. W. LOHR. 1990. Surface phenotype analysis of human monocyte to macrophage maturation. J. Leukoc. Biol. 47:490.

16. Andreesen, R., K. J. Bross, J. Osterholz, and F. Emmrich. 1986. Human macrophage maturation and heterogeneity: analysis with a newly generated set of monoclonal antibodies to differentiation antigens. Blood 67: 1257.

17. MORENO, J., and P. E. LiPSKY. 1986. Differential ability of fixed antigen-presenting cells to stimulate nominal antigen-reactive and alloreactive T4 lymphocytes. J. Immunol. 136: 3579.

18. Yamamoto, M., and A. Yano. 1985. Requirement of Ia-positive accessory cells in the MLR response against class II antigen on human B cell tumor line. J. Immunol. 135: 3887 .

19. GEPPERT, T. D., and P. E. LIPSKY. 1985. Antigen presentation by interferon-gammatreated endothelial cells and fibroblasts: differential ability to function as antigenpresenting cells despite comparable Ia expression. J. Immunol. 135: 3750. 
20. Alsalameh, S., B. Jahn, A. Krause, J. R. Kalden, and G. R. Burmester. 1991. Antigenicity and accessory cell function of human articular chondrocytes. J. Rheumatol. 18: 414.

21. JANEwAY JR., C. A. 1992. The immune system evolved to discriminate infectious nonself from noninfectious self. Immunol. Today 13:11.

22. KakiUChi, T., R. W. Chesnut, and H. M. Grey. 1983. B cells as antigen-presenting cells: the requirement for B cell activation. J. Immunol. 131: 109.

23. Kapsenberg, M. L., M. B. Teunissen, F. E. Stiekema, and H. G. Keizer. 1986. Antigen-presenting cell function of dendritic cells and macrophages in proliferative $T$ cell responses to soluble and particulate antigens. Eur. J. Immunol. 16: 345.

24. Vidard, L., K. L. Rock, and B. Benacerraf. 1992. Heterogeneity in antigen processing by different types of antigen-presenting cells: Effect of cell culture on antigen processing ability. J. Immunol. 149: 1905.

25. Jenkins, M. K., J. D. Ashwell, and R. H. Schwartz. 1988. Allogeneic non-T spleen cells restore the responsiveness of normal $\mathrm{T}$ cell stimulated with antigen and chemically modified antigen-presenting cells. J. Immunol. 140: 3324 .

26. Nisbet Brown, E. R., J. W. Lee, R. K. Cheung, and E. W. Gelfand. 1987. Antigen-specific and -nonspecific mitogenic signals in the activation of human $T$ cell clones. J. Immunol. 138: 3713.

27. Jenkins, M. K., P. S. Taylor, S. D. Norton, and K. B. Urdahl. 1991. CD28 delivers a costimulatory signal involved in antigen-specific IL-2 production by human T cells. J. Immunol. 147: 2461.

28. Ruppert, J., and J. H. Peters. 1991. IL-6 and IL-1 enhance the accessory activity of human blood monocytes during differentiation to macrophages. J. Immunol. 146: 144.

29. Strober, W., and S. P. James. 1990. Immunoregulatory function of human autoreactive $\mathrm{T}$ cell lines and clones. Immunol. Rev. 116: 117.

30. Kawakami, K., Y. Yamamoto, K. Kakimoto, and K. Onoue. 1989. Requirement for delivery of signals by physical interaction and soluble factors from accessory cells in the induction of receptor-mediated $\mathrm{T}$ cell proliferation. Effectiveness of IFNgamma modulation of accessory cells for physical interaction with $\mathrm{T}$ cells. $\mathrm{J}$. Immunol. 142: 1818.

31. Dustin, M. L., R. Rothlein, A. K. Bhan, C. A. Dinarello, and T. A. Springer. 1986. Induction by IL 1 and interferon-gamma: tissue distribution, biochemistry, and function of a natural adherence molecule (ICAM-1). J. Immunol. 137:245.

32. Freedman, A. S., G. J. Freeman, K. Rhynhart, and L. M. Nadler. 1991. Selective induction of B7/BB-1 on interferon-gamma stimulated monocytes: a potential mechanism for amplification of $\mathrm{T}$ cell activation through the CD28 pathway. Cell. Immunol. 137: 429.

33. Ruppert, J., D. Friedrichs, H. Xu, and J. H. Peters. 1991. IL-4 decreases the expression of the monocyte differentiation marker CD14, paralleled by an increasing accessory potency. Immunobiol. 182: 449.

34. Lacour, M., U. Rudolphi, M. Schlesier, and H. H. Peter. 1991. Type II collagen-specific $\mathrm{T}$ cells in healthy donors [letter; comment]. Eur. J. Immunol. 21: 1092 .

Dr. Michael Schlesier, Abteilung Rheumatologie und klinische Immunologie, Medizinische Klinik, Hugstetter Str. 55, 79106 Freiburg, Germany 